\title{
Expressed emotions and coping among the relapsed persons with alcohol dependence syndrome: A Comparative Study
}

\author{
Backiyaraj Shanmugam ${ }^{1}$, Basudeb Das ${ }^{2}$, Dipanjan Bhattacharjee ${ }^{3}$, Sinu Ezhumalai ${ }^{4}$ \\ ${ }^{1}$ National Institute of Mental Health and Neurosciences, Bangalore. \\ ${ }^{2}$ Professor, Department of Psychiatry, Central Institute of Psychiatry, Kanke, Ranchi. \\ ${ }^{3}$ Associate Professor, Department of Psychiatric Social Work, Central Institute of Psychiatry, Kanke, \\ Ranchi. \\ ${ }^{4}$ Associate Professor, Department of Psychiatric Social Work, National Institute of Mental Health and \\ Neurosciences, Bangalore. \\ Corresponding author: Dr. Sinu Ezhumalai \\ Email-esinu27@gmail.com
}

\begin{abstract}
Background: Alcohol dependence is a global public health issue; it is a chronic and relapsing illness. Relapse is multifaceted by both neurobiological and psychosocial processes. The aim of the study was to examine the expressed emotions and coping among persons with alcohol dependence.

Methodology: The study was descriptive and hospital-based. A purposive sampling technique was used. This study was conducted at the Centre for Addiction Psychiatry, CIP, Ranchi. The total sample size was 50. Twenty-five persons with alcohol dependence who relapsed within six months following treatment formed a study group. Another 25 persons with alcohol dependence who were abstinent for a minimum period of six months after treatment formed a comparative group. Ways of Coping Questionnaire and the Level of expressed emotions Scale were used, and informed consent was taken from the participants. Chisquare and independent sample 't' test, Pearson's correlation was used to analyse the data.

Results: Mean age of relapsed patients was 35.3 years ( $\mathrm{S} . \mathrm{D} \pm 7.6$ ), and abstinent patients were $35.4 \mathrm{yrs}$. (S.D \pm 6.8 ), years of education of relapsed patients was 12 yrs. \pm 2.63 and 11.6 yrs. \pm 3.26 in abstinent patients. A majority $(60 \%)$ of relapsed patients were from rural background, $92 \%$ in the abstinent group were employed. $60 \%$ of abstinent patients had a family history of alcohol dependence. Abstinent patients had scored significantly high in all the domains of ways of coping. Relapsed patients had higher scores in perceived lack of emotional support, perceived irritability, perceived intrusiveness, and perceived criticism compared to abstinent patients

Conclusion: The study provided further evidence that coping and perceived expressed emotions significantly influenced relapse among persons with alcohol dependence.
\end{abstract}

Keywords: alcohol dependence, relapse, abstinent, coping, expressed emotions.

(Paper received $-20^{\text {th }}$ July 2021, Peer review completed $-15^{\text {th }}$ August 2021)

(Accepted $-23^{\text {rd }}$ August 2021, Published $-5^{\text {th }}$ January 2022)

\section{INTRODUCTION}

Alcohol dependence is a global public health issue; it is a chronic and relapsing illness with different factors influencing its initiation and maintenance [1]. Relapse is a multifaceted and dynamic phenomenon determined by both neurobiological and psychosocial processes. Although short-term treatment of this condition is relatively effective, preventing relapse is more challenging. Most of the patients relapse within a year of starting treatment, with the first three months being the most vulnerable period. Relapse can be a frustrating experience and usually has several adverse consequences for patients and caregivers [2]. Many researchers described that relapse as a process rather than as a detached event [3]. Several authors have 
defined relapse and its related concepts; relapse is a gradual process with distinct stages [4]; mental health professionals must understand the differentiation between lapses, relapse, and prolapse. It helps to plan for interventions, lapse as initial set-back after the attempt to maintained abstinence. In contrast, a relapse is defined as a return to previous dependence pattern of use and prolapse is the patient may gain a positive outcome of a lapse, with manage to abstinent and direction towards positive behaviour changes [5-7].

Negative emotions, external pressures, and overconfident/ seemingly irrelevant decisions in high-risk situations for the first use of a substance lead to subsequent relapse [8]. Furthermore, craving, low self-efficacy, and low family support are among known relapse-related psychosocial factors [9]. A person who perceived high social support was positively associated with increased motivation or confidence in change and reduced alcohol use [10]. Education and job profile determine perceived support from family [11], and social support predicts relapse and recovery [12]. Strong self-efficacy enables the individual to cope with such high-risk situations and maintain abstinence [8]. The person with higher self-efficacy has more time strength against relapse than drug dependent with low rate self-efficacy. Family factors play a significant role in enhancing self-efficacy study found that married people have high self-efficacy than unmarried. The education and employment status of the parents determines their children's self-efficacy if parents have higher education and stable employment proven to have high self-efficacy in their children who are seeking treatment for addiction [13]. Many studies have shown that self-efficacy is a predictor of treatment outcome, decreases the quantity of alcohol use, and determines alcohol consumption in the future, up to one year [14]. However, another study found that higher self-efficacy predicts less substance use in only three months [15]. Resilience, self-esteem, self-efficacy, and self-control are interconnected [16]; low self-esteem has a strong association with substance use and crime [17], although increased self-esteem is the predictor of avoidance of drug use [18]. Low self-esteem connected with poor coping [19]; effective coping strategies in high-risk situations are better to predict abstinent and less drinking, better reliance on maladaptive coping styles. Coping is defined as the use of cognitive and behavioural strategies to manage internal and external stressful situations.

Effective coping strategies such as leaving the situation and positive self-talk are less chance to relapse [20], and drug and alcohol-dependent were emotion-oriented. First, accepting responsibility was the most common way of coping in the high-risk situation; secondly, planful problem solving and self-controlling finally escape- avoidance and seeking social support among the alcohol dependence [21]. Lesser positive thinking and avoidance coping strategies were associated with relapse [22-23]. Involvement in recreational activities, faith in religious rituals such as chanting, reading spiritual texts and attending prayer are more effective coping strategies [24]. Avoidant coping strategies may briefly help escape from the stressful situation but are not helpful in long-standing abstinent from alcohol use. It is associated with greater use of alcohol and relapse [24-27].

Expressed emotions are one of the triggering factors for relapse in vulnerable people, even on regular treatment [28] and a stronger predictor of relapse in patients with long-standing illnesses [29]. Family emotional over-involvement was a significant predictor of relapse among alcohol dependence [30], and Perceived criticism was associated with earlier and more frequent relapses [31]. Late-onset alcohol dependence was associated with a high level of expressed emotions [32]. Many studies were conducted on expressed emotions in severe psychiatric illnesses such as schizophrenia, mood disorder, and OCD; however, limited Indian studies were conducted on EE among alcohol dependence [33]. Family factors play a significant role in the recovery of a person with substance use disorder. Many components are involved in determining relapse or abstinence among alcohol dependence, psychosocial factors have a significant role, and it is an extensive area. Few studies conducted on factors associated with relapse, although less attention to perceived expressed emotions and coping strategies, have played a significant role in recovery and relapse. Therefore, this study examines coping and expressed emotion among the relapsed and abstinent persons with alcohol dependence syndrome. 


\section{METHODOLOGY}

The study was conducted at S.S.Raju Centre for Addiction Psychiatry and Outpatient department in Central institute Psychiatry, Ranchi. The study was cross-sectional comparative study design, and purposive sampling was used. The sample consisted of 50 individuals with alcohol dependence, 25 relapsed patients of alcohol dependence, who relapsed within the next six months after had received treatment for their conditions were selected from the in-patient setting of S.S.Raju Centre for Addiction Psychiatry at Central Institute of Psychiatry. Another 25 patients with alcohol dependence who, following treatment for their condition, had managed to remain abstinent for a minimum period of 6 months were selected from the outpatient department.

Inclusion criteria aged between 23-50 years, male, married for at least two years, education status minimum fifth std and patients must have received complete treatment for their condition. Exclusion criteria history of binge drinking, co-morbid psychiatric disorders, personality disorders, major physical illnesses, organic brain syndrome or mental retardation, other substances dependence except for nicotine/caffeine, and subjects who unwilling excluded from the study, obtained ethical approval from the institutional ethics committee.

Patients were explained the nature of the study, and informed consent was obtained before data collection. Data were collected when patients were out of withdrawal symptoms or after detoxification. The Level of Expressed Emotion Scale [34] and Ways of Coping Questionnaire [35] were applied to both groups. Chisquare and independent samples ' $t$ ' test were applied, and Pearson's correlation was used to see the relationship among study variables.

\section{RESULTS}

Table 1: Socio-demographic variable of the respondents

\begin{tabular}{|c|c|c|c|c|c|}
\hline \multicolumn{2}{|c|}{ Socio-demographic variables } & $\begin{array}{c}\text { Relapsed N=25 } \\
(\text { Mean } \pm \text { SD) }\end{array}$ & $\begin{array}{c}\text { Abstinent } \\
N=25 \\
(\text { Mean } \pm \text { SD) }\end{array}$ & $t$ test & $\mathbf{p}$ \\
\hline \multicolumn{2}{|l|}{ Age (in years) } & $35.28 \pm 7.58$ & $35.36 \pm 6.81$ & 0.039 & 0.969 \\
\hline \multicolumn{2}{|c|}{ Years of education } & $11.96 \pm 2.63$ & $11.60 \pm 3.26$ & 0.429 & 0.670 \\
\hline \multicolumn{2}{|c|}{ Age of onset (in years) } & $19.76 \pm 2.78$ & $18.60 \pm 2.69$ & 1.496 & 0.141 \\
\hline \multicolumn{2}{|c|}{ Duration of dependence (in years) } & $7.48 \pm 3.98$ & $8.04 \pm 3.19$ & 0.549 & 0.586 \\
\hline \multicolumn{2}{|l|}{ No. of relapse } & $3.28 \pm 2.17$ & $2.40 \pm 1.08$ & 1.815 & 0.076 \\
\hline \multirow[t]{2}{*}{ Residence } & Rural & $15(60.0 \%)$ & $14(56.0 \%)$ & \multirow[t]{2}{*}{0.082} & \multirow[t]{2}{*}{0.774} \\
\hline & Urban & $10(40.0 \%)$ & $11(44.0 \%)$ & & \\
\hline \multirow[t]{2}{*}{ Occupation } & Employed & $22(80.0 \%)$ & $23(92.0 \%)$ & \multirow[t]{2}{*}{0.222} & \multirow[t]{2}{*}{1.000} \\
\hline & Unemployed & $3(12.0 \%)$ & $2(8.0 \%)$ & & \\
\hline \multirow[t]{2}{*}{ Religion } & Hindu & $21(84.0 \%)$ & $16(64.0 \%)$ & \multirow[t]{2}{*}{2.547} & \multirow[t]{2}{*}{0.196} \\
\hline & Others & $4(16.0 \%)$ & $9(26.0 \%)$ & & \\
\hline \multirow{2}{*}{ Family type } & Nuclear & $19(76.0 \%)$ & $18(72.0 \%)$ & \multirow[t]{2}{*}{0.104} & \multirow{2}{*}{0.747} \\
\hline & Joint & $6(24.0 \%)$ & $7(28.0 \%)$ & & \\
\hline \multirow[t]{2}{*}{ Family history } & Present & $14(56.0 \%)$ & $15(60.0 \%)$ & \multirow[t]{2}{*}{0.082} & \multirow[t]{2}{*}{0.774} \\
\hline & Absent & $11(44.0 \%)$ & $10(40.0 \%)$ & & \\
\hline
\end{tabular}

Table 1 shows that socio-demographic variables have no significant differences in both groups. The mean age was $35.28 \pm 7.58$ years (relapsed patients) and $35.36 \pm 6.81$ years (Abstinent patients). The mean years of education were $12 \pm 3$ for the relapsed patient and abstinent patients $12 \pm 3$. Age of onset $20 \pm 3$ relapsed patients and $19 \pm 3$ abstinent patients. The mean duration of dependence was $7.5 \pm 4$ in relapsed patients and $8 \pm 3$ in abstinent patients. $90 \%$ of the participants were employed, and the majority of them belonged to the Hindu religion. In addition, $74 \%$ of the patients were hailing from a nuclear family, and $58 \%$ had a family history of substance use. 
Table 2: Comparison of level of expressed emotions and ways of coping between relapsed patients and abstinent patients

\begin{tabular}{|c|c|c|c|c|c|}
\hline Variables & Categories & $\begin{array}{l}\text { Relapsed } \\
N=25 \\
(\text { Mean } \pm \text { SD) }\end{array}$ & $\begin{array}{l}\text { Abstinent } \\
\mathrm{N}=25 \\
\text { (Mean } \pm \text { SD) }\end{array}$ & 't' test & $\mathbf{p}$ \\
\hline \multirow{4}{*}{$\begin{array}{l}\text { Level of } \\
\text { Expressed } \\
\text { Emotions }\end{array}$} & $\begin{array}{l}\text { Perceived lack of emotional } \\
\text { support }\end{array}$ & $47.76 \pm 6.61$ & $35.04 \pm 5.72$ & 7.269 & $0.001^{* * *}$ \\
\hline & Perceived irritability & $17.84 \pm 2.19$ & $14.56 \pm 1.85$ & 5.717 & $0.001^{\star \star \star}$ \\
\hline & Perceived intrusiveness & $17.80 \pm 2.58$ & $15.36 \pm 2.07$ & 3.680 & $0.01^{* *}$ \\
\hline & Perceived criticism & $12.92 \pm 1.46$ & $10.48 \pm 1.53$ & 5.749 & $0.001^{* * *}$ \\
\hline \multirow{8}{*}{$\begin{array}{l}\text { Ways of } \\
\text { coping }\end{array}$} & Confrontive coping & $11.16 \pm 2.28$ & $13.16 \pm 2.17$ & -3.17 & $0.03^{* *}$ \\
\hline & Distancing & $10.60 \pm 3.39$ & $13.16 \pm 1.54$ & -3.43 & $0.01^{* *}$ \\
\hline & Self-controlling & $11.80 \pm 2.69$ & $16.80 \pm 1.91$ & -7.56 & $0.001^{* * *}$ \\
\hline & Seeking social support & $10.68 \pm 2.47$ & $13.80 \pm 1.89$ & -5.00 & $0.001^{* * *}$ \\
\hline & Accepting responsibility & $6.60 \pm 1.93$ & $9.40 \pm 1.63$ & -5.52 & $0.001^{* \star \star}$ \\
\hline & Escape avoidance & $12.36 \pm 3.16$ & $15.48 \pm 1.96$ & -4.19 & $0.001^{* * *}$ \\
\hline & Planful problem solving & $10.72 \pm 2.99$ & $13.24 \pm 2.22$ & -3.38 & $0.01^{* *}$ \\
\hline & Positive reappraisal & $11.40 \pm 4.24$ & $16.28 \pm 1.86$ & -5.26 & $0.001^{* * *}$ \\
\hline
\end{tabular}

Table 2 shows that there was a significant difference between both groups. Relapsed patients scored significantly high in perceived lack of emotional support $(\mathrm{p}<0.001)$, irritability $(\mathrm{p}<0.001)$, intrusiveness $(\mathrm{p}$ $<0.01)$, criticism $(\mathrm{p}<0.001)$ from their family, but abstinent patients perceived lesser than relapsed patients. Significant differences found among all sub-domains of coping, abstinent patients had scored higher respectively, Self-controlling ( $p<0.001)$, Accepting responsibility $(p<0.001)$, Positive reappraisal $(p<0.001)$, seeking social support $(\mathrm{p}<0.001)$, and escape avoidance $(\mathrm{p}<0.001)$, Distancing $(\mathrm{p}<0.01)$, Planful problem solving $(p<0.01)$, and Confronting coping $(p<0.01)$. Abstinent patients adopted all the ways of coping when they were in high-risk situations.

\section{DISCUSSION}

Central Institute of Psychiatry Ranchi, Jharkhand, is a premier institution for mental health-related conditions in India. The British established in 1918, initially named the Ranchi European Lunatic Asylum. The country's first Occupational therapy started in 1922, and the first draft of the bill of mental health Act 1987 was written at CIP [36]. The S.S Raju Centre for Addiction Psychiatry, a sixty-bedded de-addiction centre, caters to the patients seeking treatment for substance use disorder, most common of which are alcohol, cannabis, heroin and other drug dependence. The majority of the patients visiting the centre belong to the Jharkhand, Bihar, WB, UP, MP, and Chhattisgarh. In this study, $90 \%$ of the participants belonged to Ranchi and nearby districts. A woman seeking treatment alone for alcohol dependencies is not common primarily; they had to visit the hospital and sought treatment for their psychiatric conditions, along with problematic substance use, the main reason behind excluding female patients from the study. No significant difference in socio-demographic variables of age, year of education, age of onset, years of dependence, employment status, family type, and family history of substance use between the relapsed and abstinent patients of alcohol dependence in this study, like previous studies [22,37]. Although the relapsed patient had slightly high numbers of relapses in the past compared to abstinent patients, the high number of the previous relapse associated with predictors in future relapses, like earlier studies [22, 37-38].

Relapsed patients have perceived significantly high expressed emotions from their families compared to abstinent patients in the present study; Relapse patients perceived high criticism, irritability, intrusiveness, and lack of emotional support. These factors are the most potent in determining relapse, like previous studies [12, 30-31, 39]. Effective coping and relapse are moving opposite directional to determine in relapse. In the present study, abstinent patients had scored high in all sub-domain of the way of coping. Self-control, seeking social support, escape avoidance and positive reappraisal were the most common ways of coping 
than confronting, planful problem solving and distancing of coping among abstinent patients, similar to previous studies $[21,23,37,40]$. It shows that abstinent patients have adopted all the ways of coping when compared to the relapse group. They might adopt more than one coping strategy in high-risk situations or use different coping strategies in different positions. The present study found that Escape- Avoidance coping is significantly higher among abstinent patients; this finding contrasts with previous studies [24-25].

The major limitation of this study was the small sample size. The study included only the male gender, samples collected in limited geographical areas and not studied family function and dynamics, which would influence relapse, and biological factors were not considered. Thus, these findings cannot be generalised to other substance dependence.

\section{CONCLUSION}

This study highlights that coping and expressed emotions play a significant role in abstinence and relapse among alcohol dependents. Abstinent patients had adopted all the ways of coping strategies and considerably connected with abstinence. Relapsed patients had perceived high expressed emotions than abstinent. Expressed emotion is strongly associated with relapse. This study provides further evidence that psychosocial factors such as coping and high expressed emotions influence relapse among alcoholdependents. Mental health professionals need to consider coping and expressed emotions in the treatment plan, especially when dealing with relapse persons with alcohol dependence.

\section{REFERENCES}

1. Brady KT, Sinha R. Co-occurring mental and substance use disorders: the neurobiological effects of chronic stress. Am J Psychiatry 2005;162(8):1483-93.

2. Ciccocioppo RR, Hyytia P. The genetic of alcoholism: learning from 50 years of research. Addict Biol 2006; 11;193-4.

3. Steckler G, Witkiewitz K, Marlatt GA. Relapse Prevention Principles of Addiction Vol 11 st Edition Edited by Miller PM Elsevier 2013.

4. Gorski T, Miller M. Staying Sober: A Guide for Relapse Prevention. Independence, MO: Independence Press; 1986.

5. Menon J, Kandasamy A. Relapse prevention. Indian J Psychiatry 2018:S2:473-8.

6. Wheeler JG, George WH, Stoner SA. Enhancing the relapse prevention model for sex offenders: Adding recidivism risk reduction therapy to target offenders' dynamic risk needs. In: Marlatt GA, Donovan DD, editors. Relapse Prevention. 2. New York: Guilford Publications; 2005.

7. Marlatt GA, Witkiewitz K. Relapse prevention in Alcohol and drug problems Relapse Prevention: Maintenance Strategies in Treatment of Addictive Behaviours 2nd Edition. Edited by Marlatt GA, Donovan DM Guilford Press 2005.

8. Dawson DA, Goldstein RB, Grant BF. Rates and correlates of relapse among individuals in remission from DSM-IV alcohol dependence: A 3-year follow-up. Alcohol Clin Exp Res 2007;31:2036-45.

9. Ibrahim F, Kumar N. Factors effecting drug relapse in Malaysia: An empirical evidence. Asian Social Science 2009;5:37-9.

10. Marlatt GA, Gordon JR. Relapse prevention. Maintenance strategies in addictive behavioural change. New York: Guilford Press; 1980.

11. Dixit S, Chauhan VS, Azad S. Social Support and Treatment Outcome in Alcohol Dependence Syndrome in Armed Forces. J Clin Diagn Res. 2015;9(11).

12. Atadokht A, Hajloo N, Karimi M, Narimani M. The Role of Family Expressed Emotion and Perceived Social Support in Predicting Addiction Relapse, Int J High Risk Behav Addict 2015;4(1):e2 1250.

13. Abdollahi Z, Taghizadeh F, Hamzehgardeshi Z, Bahramzad O. Relationship between addiction relapse and self-efficacy rates in injection drug users referred to Maintenance Therapy Center of Sari, 1391. Glob J Health Sci 2014;6(3):138-44.

14. Maisto S. A, Connors G. J, Zywiak W. H. Alcohol treatment changes in coping skills, self-efficacy, and levels of alcohol use and related problems 1 year following treatment initiation. Psychol Addict Behav 2000;14(3):257.

15. Dolan SL, Martin RA, Rohsenow DJ. Self-efficacy for cocaine abstinence: pretreatment correlates and relationship to outcomes. Addict Behav 2008;33(5):675-88. 
16. Yang C, Zhou Y, Cao Q, Xia M, An J. The Relationship between Self-Control and Self-Efficacy among Patients with Substance Use Disorders: Resilience and Self-Esteem as Mediators. Front Psychiatry 2019;10:388.

17. Alavi HR. The role of self-esteem in tendency towards drugs, theft and prostitution. Addict Health 2011;3(34):119-24.

18. Kounenou K. Exploration of the relationship among drug use \& alcohol drinking, entertainment activities and self-esteem in Greek University students. Proc Soc Behav Sci 2010;2(2):1906-10.

19. Zhai H, Yang Y, Sui H, Wang W, Chen L, Qiu X, et al. Self-Esteem and Problematic Drinking in China: A Mediated Model. PLoS One 2015;10(10).

20. Brooks AT, Lòpez MM, Ranucci A, Krumlauf M, Wallen GR. A Qualitative Exploration of Social Support during Treatment for Severe Alcohol Use Disorder and Recovery. Addict Behav Rep 2017;6:76-82.

21. Sudraba, A. Millere, L. Deklava, E. Millere, Z. Zumente, K. Circenis, I. Millere, Stress Coping Strategies of Drug and Alcohol Addicted Patients in Latvia, Proc Soc Behav Sci 2015;205:632-6.

22. Sureshkumar K, Kailash S, Dalal PK, Reddy MM, Sinha PK. Psychosocial Factors Associated with Relapse in Patients with Alcohol Dependence. Indian J Psychol Med 2017;39(3):312-5.

23. Sarada, D.K., \& Radharani, D. A Study to Compare the Coping Strategies Among Abstinent And Relapsed Individuals with Alcohol Dependence. J Dental Med Sci 2017;16(7):24-6.

24. Nadkarni A, Dabholkar H, McCambridge J, et al. The explanatory models and coping strategies for alcohol use disorders: an exploratory qualitative study from India. Asian J Psychiatry 2013;6(6):521-7.

25. Bonin MF, McCreary DR, Sadava SW. Problem drinking behavior in two community-based samples of adults: Influence of gender, coping, loneliness, and depression. Psychol Addict Behav 2000:14:151-61.

26. Cooper ML, Frone MR, Russell M, Mudar P. Drinking to regulate positive and negative emotions: A motivational model of alcohol use. J Personal Soc Psychol 1995;69:990-1005.

27. Willis, AS, Wallston, KA, Johnson, KRS. Tobacco and alcohol use among young adults: Exploring religious faith, locus of health control, and coping strategies as predictors. In TG Plante, \& AC Sherman (Eds.), Faith and health: Psycho-logical perspectives New York, NY, US: Guilford Press. 2001.

28. Bhugra D, McKenzie K. Expressed emotion across cultures. Adv Psychiatr Treat 2003:9(5):342-8.

29. Brown GW. The discovery of expressed emotion: Induction or deduction? In: Leff J, Vaughn C, editors. Expressed emotion in families. New York: Guilford Press; 1985.

30. Burling TA, Reilly PM, Moltzen JO, Ziff DC. Self-eficacy and relapse among inpatients with drug and alcohol abuse. J Stud Alcohol 1989;50:354-60.

31. Shobhana M, Charan TK, Arun Y, Pavithra R, and Chandini R. Expressed emotion and relapse of alcohol use disorder, Int J Scientific Res Publn 2015;5(4).

32. Reddy AS, Jagannathan A. Predictors of coping and perceived expressed emotions in persons with alcohol dependence in India: a pilot study. Asian J Psychiatry 2017;28:38-40.

33. Sadath A, Kumar R, Karlsson M. Expressed Emotion Research in India: A Narrative Review. Indian J Psychol Med 2019;41(1):18-26.

34. Cole JD, Kazarian SS. The Level of Expressed Emotion Scale: a new measure of expressed emotion. J Clin Psychol 1988;44(3):392-7.

35. Folkman S, Lazarus RS, Dunkel-Schetter C, DeLongis A, Gruen R. The dynamics of a stressful encounter: Cognitive appraisal, coping and encounter outcomes. J Personal Soc Psychol 1986;50:992-1003.

36. Mattoo SK, Chakrabarti S, Anjaiah M. Psychosocial factors associated with relapse in men with alcohol or opioid dependence. Indian J Med Res 2009;130:702-8.

37. Nizamie SH, Goyal N, Haq MZ, Akhtar S. Central Institute of Psychiatry: A tradition in excellence. Indian J Psychiatry 2008;50(2):144-8.

38. Greenfield SF, Brooks AJ, Gordon SM, Green CA, Kropp F, McHugh RK, Lincoln M, Hien D, Miele GM. Substance abuse treatment entry, retention, and outcome in women: A review of the literature. Drug Alcohol Depend 2007;86(1):1-21.

39. O'Farrell TJ, Hooley J, Fals-Stewart W, \& Cutter, H. S. G. Expressed emotion and relapse in alcoholic patients. Journal of Consulting and Clinical Psychology 1998; 66(5): 744-752.

40. Van Trieu N, Uthis P, Suktrakul S. Alcohol dependence and the psychological factors leading to a relapse: a hospital-based study in Vietnam. J Health Res 2021;35(2):118-31.

Acknowledgements: This work was supported by Indo-US Fogarty Post-Doctoral Training in Chronic Non-Communicable Disorders across Lifespan Grant \#1D43TW009120 (Sinu Ezhumalai, Post-Doctoral Fellow; LB Cottler, PI).

Funding: This study was funded by Ministry of Health \& Family Welfare, Govt of India in Collaboration with Central Institute of Psychiatry, Ranchi under Manpower Development Scheme in Mental Health (2014-2016).

Conflict of Interest: Nil 